\title{
Simultaneous endoscopic submucosal dissection for synchronous double early gastric cancer
}

\author{
Akiyoshi Kasuga $\cdot$ Yorimasa Yamamoto $\cdot$ Junko Fujisaki $\cdot$ Kazuhisa Okada • \\ Masami Omae · Akiyoshi Ishiyama - Toshiaki Hirasawa $\cdot$ Akiko Chino \\ Tomohiro Tsuchida $\cdot$ Etsuo Hoshino $\cdot$ Masahiro Igarashi
}

Received: 10 July 2012/Accepted: 10 November 2012/Published online: 28 November 2012

(c) The International Gastric Cancer Association and The Japanese Gastric Cancer Association 2012

\begin{abstract}
Background This study aims to evaluate the safety and efficacy of simultaneous endoscopic submucosal dissection (ESD) for synchronous double early gastric cancers.

Methods We retrospectively evaluated 832 single gastric cancers from 789 patients treated by single ESD (single group) and 124 synchronous double cancers from 62 patients treated by simultaneous ESD (simultaneous group).

Results The overall rate of en bloc resection and curative resection was comparable between the two groups. Procedure time was significantly longer in the simultaneous group than in the single group $(131.0 \pm 66.5$ and $94.8 \pm 64.1 \mathrm{~min}$, respectively, $P<0.001)$. White blood cell count on the day after ESD was significantly higher in the simultaneous group $(9310 \pm 2774 / \mu \mathrm{l})$ than in the single group $(8633 \pm 2341 / \mu 1)(P=0.032)$. Length of fasting period after ESD was $1.1 \pm 0.5$ days in the single group and $1.4 \pm 1.1$ days in the simultaneous group $(P=0.082)$. Complications were more frequent in the simultaneous group than in the single group (11.3 vs. $5.4 \%$, respectively), but the difference was not significant $(P=0.082)$. Complication rate per one lesion did not differ between the two groups (5.6 vs. $5.4 \%$, respectively, $P=0.914$ ).
\end{abstract}

\footnotetext{
A. Kasuga $(\varangle) \cdot$ Y. Yamamoto · J. Fujisaki · K. Okada ·

M. Omae · A. Ishiyama - T. Hirasawa - A. Chino ·

T. Tsuchida $\cdot$ E. Hoshino $\cdot$ M. Igarashi

Department of Gastroenterology, Cancer Institute Hospital,

Japanese Foundation for Cancer Research, 3-10-6 Ariake,

Koto-ku, Tokyo 135-8550, Japan

e-mail: akiyoshi_81@hotmail.com
}

\section{A. Kasuga}

Department of Medical Oncology, School of Medicine,

Kyorin University, Tokyo, Japan
Multivariate analysis showed procedure time longer than $150 \mathrm{~min}$ was independently predictive for complications of simultaneous ESD $(P<0.042$, odds ratio $=6.094)$. Large tumors, upper portion location and tumors not in the standard guideline criteria were significantly associated with long procedure time.

Conclusions Simultaneous ESD for synchronous early gastric cancer can be a feasible and safe option, and it can reduce hospital stay. These results need to be validated by further studies.

Keywords Stomach neoplasms - Endoscopy · Gastroscopy

\section{Introduction}

Endoscopic submucosal dissection (ESD) is recognized as a treatment for early gastric cancer associated with a minimal risk of regional lymph node metastasis. Furthermore, it has increasingly gained acceptance in Western countries, because it improves the completeness of en bloc resection of early gastric cancer [1-3].

In studies conducted on patients with surgically resected stomachs, the synchronous multiplicity of gastric cancer is well known, and the frequency of such multiple cancers has been reported to range from 4.8 to $20.9 \%$ at several institutions [4-9]. Accurate detection of synchronous multifocal gastric cancer is mandatory for the successful management of gastric cancer, and the entire stomach should be examined with particular care during endoscopic procedures, especially when endoscopic resections of tumors are to be performed [10].

Although ESD contributes to preserving most of the stomach, the risk of synchronous and metachronous gastric 
cancer developing at other sites in the stomach has become a major problem. There have been only few reports regarding the treatment strategies for synchronous multiple early gastric cancers. We have performed simultaneous ESD for synchronous multiple early gastric cancer. This study was designed to evaluate the safety and efficacy of simultaneous ESD for synchronous double early gastric cancer by comparing with single ESD for single early gastric cancer.

\section{Materials and methods}

Definition of synchronous and metachronous multiple cancer

There is no consensus regarding the distinction between actual metachronous gastric cancer and missed synchronous gastric cancer [11]. However, in this study, we defined multiple cancer detected at the time of ESD as synchronous and a second cancer found after ESD as metachronous (irrespective of the time elapsed since ESD).

\section{Patients}

The cases reviewed for this study included 1111 early gastric cancers in 944 consecutive patients who underwent ESD at Cancer Institute Hospital of the Japanese Foundation for Cancer Research between March 2005 and February 2010. The patients were classified based on the guideline criteria proposed by the Japanese Gastric Cancer
Association including the expanded criteria proposed by Gotoda et al. [1, 12]. In our hospital, 228 synchronous multiple gastric cancers from 110 patients were treated by ESD. We focused on evaluation of simultaneous ESD for synchronous double early gastric cancers in this study. The study comprised cases that were resected in 1 day by ESD, but excluded those in which more than two synchronous lesions were resected during the same procedure (40 lesions from 12 patients), double lesions were not resected on the same day (16 lesions from 8 patients), lesions were located in the remnant stomach because of prior surgery for malignancy or peptic ulcer (52 lesions from 42 patients), a gastric tube had been used after esophagotomy as a surgery for esophageal cancer ( 9 lesions from 7 patients), cases of synchronous early gastric cancer resected as one piece by ESD (28 lesions from 14 patients) and cases of synchronous multiple early gastric cancer treated by ESD with lesions at other sites in the stomach that were outside of the expanded histological criteria for endoscopic resection treated by surgery (10 lesions from 10 patients) (Fig. 1). A total of 956 lesions from 851 patients were included in the study. Eight hundred thirty-two single gastric cancers from 789 patients treated by single ESD and 124 synchronous double cancers from 62 patients treated by simultaneous ESD were evaluated.

ESD procedure

ESD was performed by, or conducted under the supervision of, expert endoscopists certified by the Japan Society

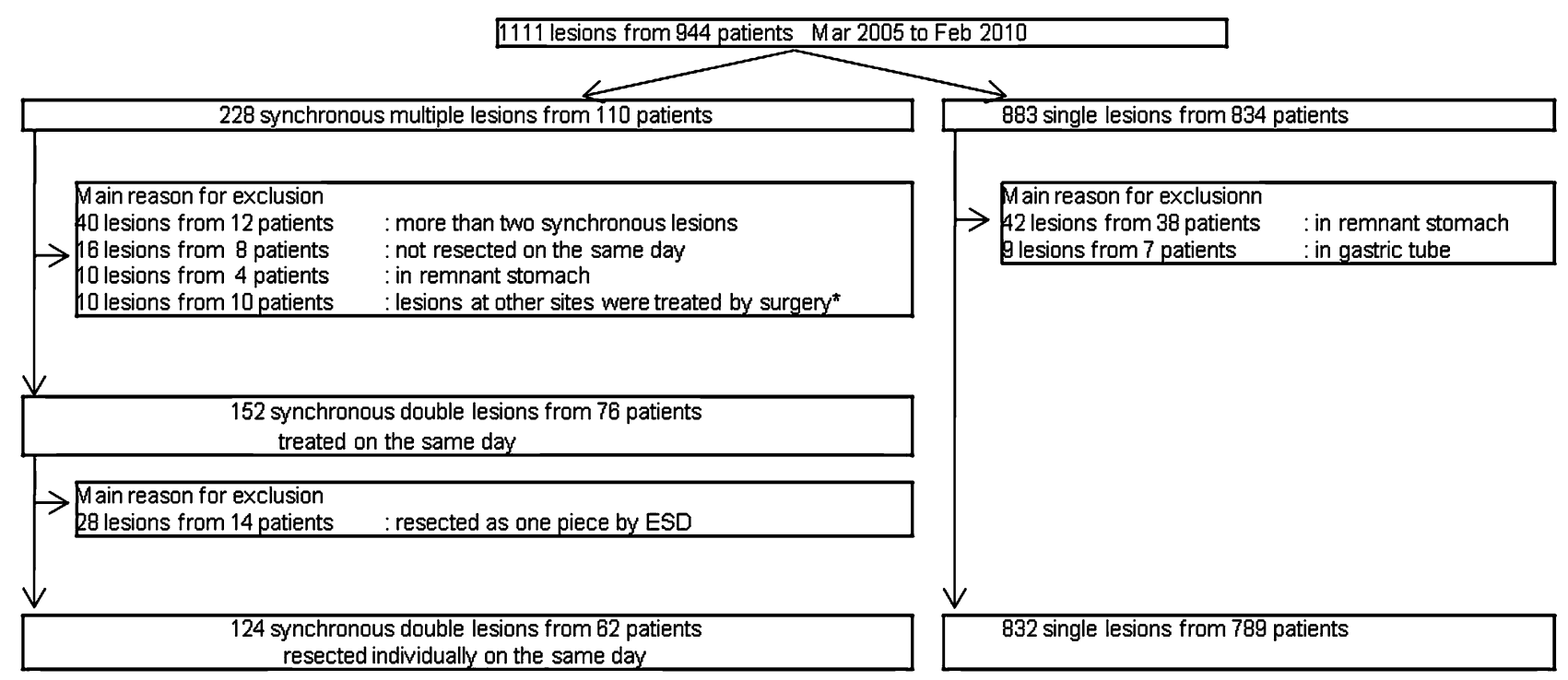

* they have early gastric cancer treated by ESD with lesions at other sites in the stomach which were outside of the expanded histological criteria for endoscopic resection treated by surgery

Fig. 1 Patient selection of synchronous multiple early gastric cancers treated by ESD: the study included 62 patients with synchronous double cancers treated with simultaneous ESD 
of Gastrointestinal Endoscopy. As preoperative procedures, chromoendoscopy (using indigo carmine), magnification endoscopy with narrow-band imaging (ME-NBI) and circumferential biopsies of a lesion were employed for defining the carcinomatous area, and endoscopic ultrasonography (EUS) was performed as needed for assessment of invasion depth. ESD, conducted under anesthesia with midazolam and pethidine hydrochloride, began with the identification of the lesions and marking around them with spotty cautery using argon plasma coagulation. Lesions were completely removed by submucosal dissection using an insulated-tip knife (IT knife) or IT knife 2 (Olympus Optical, Tokyo, Japan). Whenever active bleeding was noticed, endoscopic hemostasis was performed either with the knife itself or with hemostatic forceps (FD-410LR; Olympus, Tokyo). All visible vessels on the artificial ulcer were coagulated using hemostatic forceps even if there was no evidence of bleeding at the end of ESD.

Simultaneous ESD was performed for double lesions. It was started by marking both lesions. After resection of a lesion on the anal side, we coagulated all visible vessels on the artificial ulcer. Then we started to resect the next lesion on the oral side (Fig. 2).

The ESD operation time was defined as the time interval between endoscopic insertion and removal.
Fig. 2 Simultaneous ESD procedure for synchronous double gastric cancer. a Image of conventional endoscopy.

b Image of conventional endoscopy with indigo-carmine dye. c Marking dots were made on the circumference of both lesions. d, e Resection of a lesion on the anal side.

f Artificial ulcers after removal of both lesions
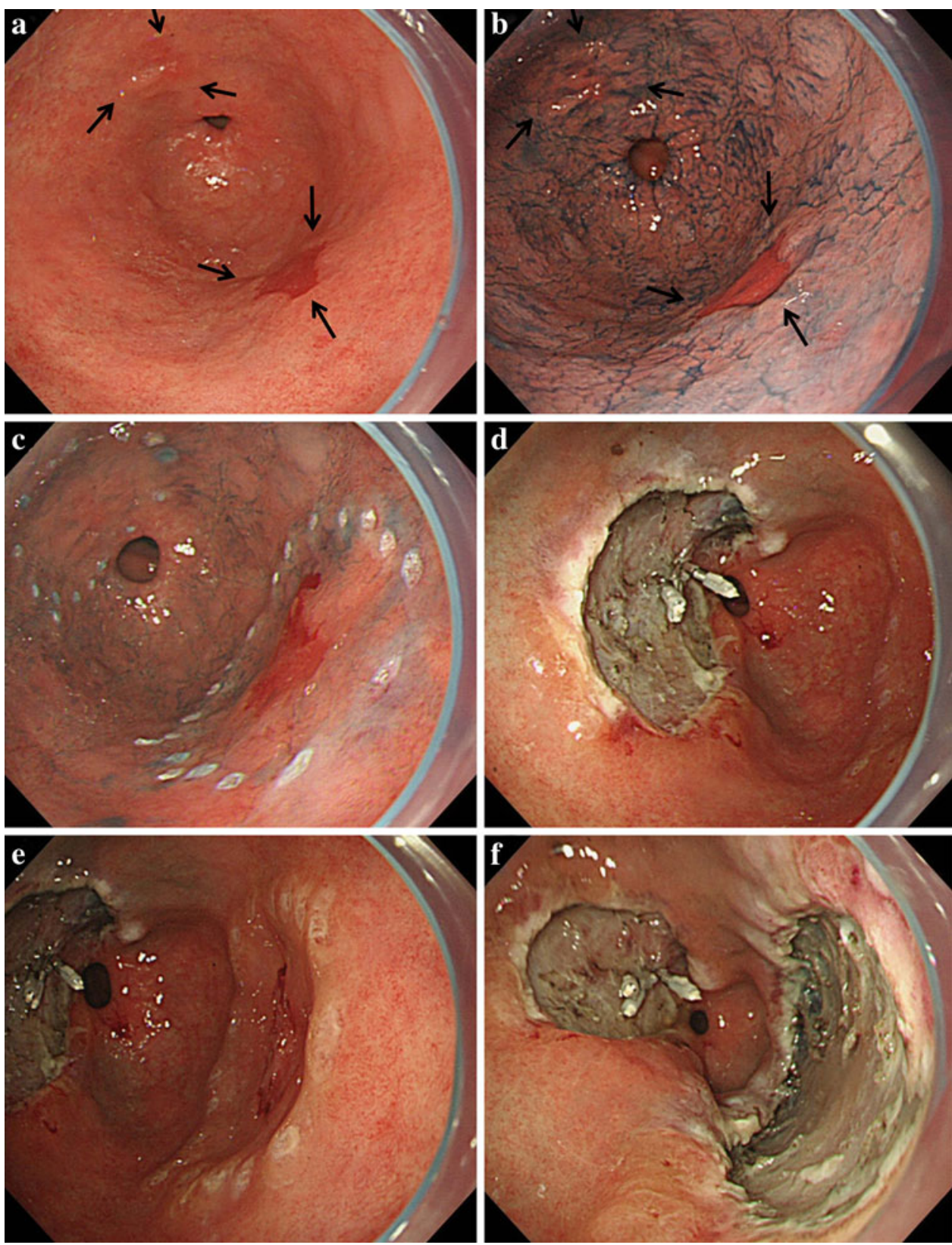
Evaluation of resected specimens

Early gastric cancers were categorized according to location, i.e., upper (U), middle (M) or lower third (L) of the stomach. All resected specimens were sectioned into 2-mm slices and evaluated by histopathological examination. The tumors were classified histopathologically according to Japanese Gastric Cancer Association (JGCA) criteria [13]. Tumor size and ulceration were determined histopathologically, and the size of the resected specimen was measured at the greatest diameter. Curability was determined histopathologically based on the expanded criteria proposed by Gotoda et al. [1]; thus, standard guideline criteria for endoscopic resection are differentiated adenocarcinoma and intramucosal cancer $20 \mathrm{~mm}$ or less in size without ulcer findings. Expanded indication criteria for differentiated adenocarcinoma are having no evidence of invasion of the submucosal layer and, regardless of tumor size, being without ulcer findings or $30 \mathrm{~mm}$ or less in size with ulcer findings, or having evidence of minute invasion of the submucosal layer (less than SM $500 \mu \mathrm{m}$ ) and being $30 \mathrm{~mm}$ or less in size. Expanded criteria for undifferentiated adenocarcinoma are having no evidence of the submucosal layer and being $20 \mathrm{~mm}$ or less in size without ulcer findings. Curative resection was regarded as a resection within the indication criteria with margins free of neoplasm (complete resection) and not having lymphatic or vascular invasion.

Data and statistical analysis

Detailed information on endoscopic images, procedures and pathological examinations was obtained from medical records. Patients and procedures were divided into simultaneous resection and single resection groups. Lesions were divided into double lesion and single lesion groups.

Operative conditions, procedural time, amount of anesthetic used during the procedures, complications such as postoperative bleeding, perforation and an operation needed for complications were compared between the simultaneous and single resection groups. Postoperative conditions, hemoglobin level, white blood cell counts on the day after $\mathrm{ESD}$, length of fasting periods in the perioperative course and length of hospital stay after ESD were evaluated. Statistical analyses were carried out using Chi-square tests, Fisher's exact test, $t$ test or Mann-Whitney $U$ test. These variables were also evaluated by a multivariate logistic regression model using the Wald statistic backward stepwise selection. The level of significance was set at $P<0.05$. The factors affecting metachronous lesions were analyzed using the Kaplan-Meier method, and a log-rank test was conducted. The analyses were performed using SPSS software.
Ethics

The study was conducted in accordance with the Declaration of Helsinki, and the study protocol was approved by the Ethics Committee of the Cancer Institute Hospital of the Japanese Foundation for Cancer Research.

\section{Results}

Patient and lesion characteristics

A total of 832 single lesions from 789 patients were treated by ESD and 124 synchronous double lesions from 62 patients were simultaneously resected by ESD on the same day.

The clinicopathological characteristics of the single and double lesions are presented in Table 1. The median patient age was 68.1 years old in the single group and 70.6 years old in the double group; thus, the patients in the double group were older than those in single group, although this did not reach statistical significance $(P=0.053)$.

The location of the lesions was comparable between the two groups. Although tumor size was comparable between the groups $(14.8 \pm 10.4 \mathrm{~mm}$ in the single group and $13.7 \pm 8.1 \mathrm{~mm}$ in the double group, $P=0.258$ ), specimen sizes were significantly larger in the single group than in the double group $(32.8 \pm 12.9 \mathrm{~mm}$ in the single group and $30.0 \pm 10.9 \mathrm{~mm}$ in the double group, $P=0.023$ ).

In the double group, the incidence of differentiated type gastric cancer was $96.8 \%$ (120/124), which was significantly $(P=0.006)$ higher than in the single group $(88.7 \%$; 739/832). The criteria according to those proposed by the Japanese Gastric Cancer Association were comparable between the groups $(P=0.144)$.

\section{Clinical outcomes of each procedure}

The clinical outcomes of each procedure are summarized in Table 2. Procedure time was significantly longer in the simultaneous resection group than in the single resection group $(131.0 \pm 66.5$ vs. $94.8 \pm 64.1 \mathrm{~min}$, respectively; $P<0.001$ ). The amounts of sedative drugs (pethidine hydrochloride and midazolam) administered during procedures were significantly larger in the simultaneous group than in the single group $(P=0.001$ and $<0.001$, respectively).

The overall rate of en bloc resection and curative resection was comparable between the two groups.

Overall, complications were more frequent in the simultaneous than in the single group, $11.3 \%(7 / 62)$ versus 
Table 1 Clinicopathological characteristics of single and double lesions

\begin{tabular}{|c|c|c|c|}
\hline & Single lesions & Double lesions & $P$ value \\
\hline \multicolumn{4}{|l|}{ Patient characteristics } \\
\hline Number $(n)$ & 789 & 62 & \\
\hline \multicolumn{4}{|l|}{ Sex } \\
\hline Male & $565(71.6 \%)$ & $44(71.0 \%)$ & 0.914 \\
\hline Female & $224(28.4 \%)$ & $18(29.0 \%)$ & \\
\hline \multicolumn{4}{|l|}{ Age (years) } \\
\hline Mean \pm SD & $68.1 \pm 9.7$ & $70.6 \pm 9.2$ & 0.053 \\
\hline Range & $33-91$ & $41-89$ & \\
\hline \multicolumn{4}{|l|}{ Lesion characteristics } \\
\hline Number $(n)$ & 832 & 124 & \\
\hline \multicolumn{4}{|l|}{ Location } \\
\hline Upper & $167(20.0 \%)$ & $19(15.3 \%)$ & 0.366 \\
\hline Middle & $307(36.9 \%)$ & $55(44.4 \%)$ & \\
\hline Lower & $358(43.0 \%)$ & $50(40.3 \%)$ & \\
\hline \multicolumn{4}{|l|}{ Tumor size (mm) } \\
\hline Mean \pm SD & $14.8 \pm 10.4$ & $13.7 \pm 8.1$ & 0.258 \\
\hline Range & $1.0-100.0$ & $2.0-43.0$ & \\
\hline \multicolumn{4}{|l|}{ Specimen size (mm) } \\
\hline Mean \pm SD & $32.8 \pm 12.9$ & $30.0 \pm 10.9$ & 0.023 \\
\hline Range & $8.0-125.0$ & $10.0-95.0$ & \\
\hline \multicolumn{4}{|l|}{ Pathological findings } \\
\hline Differentiated type & $739(88.7 \%)$ & $120(96.8 \%)$ & 0.006 \\
\hline Undifferentiated type & $94(11.3 \%)$ & $4(3.2 \%)$ & \\
\hline \multicolumn{4}{|l|}{ Guideline criteria } \\
\hline Standard guideline criteria & $519(62.3 \%)$ & $88(71.0 \%)$ & 0.144 \\
\hline Expanded indication criteria & $218(26.2 \%)$ & $27(21.8 \%)$ & \\
\hline Non-indication criteria & $96(11.5 \%)$ & $9(7.3 \%)$ & \\
\hline
\end{tabular}

$5.4 \%$ (45/832), respectively, but the difference was not significant $(P=0.082)$. Delayed bleeding and perforation were $6.5 \%(4 / 62)$ and $3.2 \%(2 / 62)$, respectively, in the simultaneous group and $4.4 \%$ (37/832) and $1.0 \%$ (8/832), respectively, in the single group. One patient in the simultaneous group needed distal gastrectomy because of bleeding during the procedure. The complication rate per one lesion did not differ between the two groups (5.6 vs. $5.4 \%$, respectively, $P=0.914$ ).

A comparison of the clinical data between the two groups is also presented in Table 2. Although WBC counts on admission were comparable $(P=0.948)$ between the two groups, WBC count on the day after ESD was significantly higher in the simultaneous resection group (9310 \pm 2774 / $\mu l)$ compared with the single resection group (8633 \pm 2341 / $\mu$ l) $(P=0.032)$. Hemoglobin levels on admission and on the day after ESD were comparable $(P=0.593$ and 0.943 , respectively) between the two groups. Length of the fasting period after ESD was $1.1 \pm 0.5$ days in the single resection group and $1.4 \pm 1.1$ days in the simultaneous resection group, but the difference was not significant $(P=0.082)$.
Clinical characteristics of the cases with complications following simultaneous ESD are shown in Table 3. Age of patients, size, locations, and guideline criteria of tumors were comparable between cases with and without complications. Procedure time was $179.0 \pm 119.0 \mathrm{~min}$ in cases with complications and $124.9 \pm 55.5 \mathrm{~min}$ in cases without complications; this difference was significant $(P=0.039)$. In addition, in multivariate analysis, a procedure time longer than $150 \mathrm{~min}$ was significantly associated with complications $(P<0.042$, odds ratio $=6.094$, $95 \%$ confidence interval $=1.070-34.718)$. Size of the larger tumor, upper portion location and tumors not in the standard guideline criteria were significantly associated with long procedure time (Table 4 ).

\section{Discussion}

The frequency of the synchronous multiplicity of gastric cancer in surgically resected stomachs has been reported to range from 4.8 to $20.9 \%$ at several institutions [4-9]. The 
Table 2 Results for single resection and simultaneous resection

\begin{tabular}{lllr}
\hline & $\begin{array}{l}\text { Single resection } \\
(832 \text { procedures })\end{array}$ & $\begin{array}{l}\text { Simultaneous resection } \\
(62 \text { procedures })\end{array}$ & $P$ value \\
\hline Procedure time (min) & & & \\
Mean \pm SD & $94.8 \pm 64.1$ & $131.0 \pm 66.5$ & $<0.001$ \\
Range & $25-480$ & $41-414$ & \\
Amount of sedative drugs & & & 0.001 \\
Pethidine hydrochloride (mg) & $43.6 \pm 18.4$ & $54.1 \pm 23.8$ & $<0.001$ \\
Midazolam (mg) & $7.4 \pm 4.0$ & $10.0 \pm 4.3$ & 0.226 \\
En-bloc resection & $822(98.7 \%)$ & $60(96.8 \%)$ & 0.769 \\
Curative resection & $723(86.8 \%)$ & $53(85.5 \%)$ & 0.082 \\
Complication & $45(5.4 \%)$ & $7(11.3 \%)$ & 0.521 \\
Delayed bleeding & $37(4.4 \%)$ & $4(6.5 \%)$ & 0.148 \\
Perforation & $8(1.0 \%)$ & $2(3.2 \%)$ & 0.069 \\
Operation needed for complication & $0(0.0 \%)$ & $1(1.6 \%)$ & 0.948 \\
WBC count (mean $\pm \mathrm{SD} / \mu \mathrm{l})$ & & & 0.032 \\
On admission & $6321 \pm 1623$ & $6307 \pm 1743$ & 0.592 \\
The next day & $8633 \pm 2341$ & $9310 \pm 2774$ & 0.943 \\
Hb (g/d) & & & 0.084 \\
On admission & $13.7 \pm 1.4$ & $13.6 \pm 1.4$ & $12.9 \pm 1.5$ \\
The next day & $12.9 \pm 1.4$ & $7.4 \pm 2.0$ & \\
Length of fasting period (days) & $1.1 \pm 0.5$ & & \\
Length of hospital stay (days) & $6.7 \pm 2.0$ & & \\
\hline
\end{tabular}

rate of synchronous gastric cancers treated with endoscopic resection has been estimated at 6.6 to $19.2 \%$ [11, 14-17]; in our institution it was $11.7 \%$ (110 out of 944 patients). However, few reports have discussed endoscopic treatment strategies for synchronous gastric cancer. There is no consensus regarding the distinction between actual metachronous gastric cancer and missed synchronous gastric cancer. Some previous reports defined a second cancer found within 1 year after endoscopic resection as "synchronous" and a second cancer found after more than 1 year as "metachronous." In this study, however, we defined a multiple cancer detected at the time of ESD as synchronous, because we have evaluated the safety and efficacy of simultaneous ESD for synchronous multiple early gastric cancer.

In the present study, white blood cell counts on the day after ESD were significantly higher in the simultaneous resection group than in the single resection group. Although the hemoglobin level and the fasting period were comparable between the two groups, hospital stay was significantly longer in the simultaneous group than in the single resection group, but the difference was less than 1 day. Operative time was significantly longer in the simultaneous resection group than in the single resection group. Complications such as perforation and delayed bleeding were more common in the simultaneous resection group than in the single resection group, but the difference was not significant and the complication rate per one lesion did not differ between the two groups (5.6 vs. $5.4 \%$ ). Simultaneous ESD can be a feasible and safe option, and it can reduce hospital stay and overall medical expenses by the simultaneous resection of two cancers on the same day. In our study, multivariate analysis for complications by simultaneous ESD showed that procedure time longer than 150 min was significantly associated with complications. Size of the larger tumor, upper portion location and tumors not in the standard guideline criteria were associated with long procedure times. If we expect that the procedure time will be longer than $150 \mathrm{~min}$ for cases with synchronous early gastric cancer, resection on separate days might be a good option.

Previous reports described that lesions in the upper stomach and large size and long procedure time were associated with complications for single ESD [18, 19]. Our results for the simultaneous ESD for the double lesions were almost the same as described in these previous reports for single ESD. These results for the simultaneous ESD need to be validated by further studies.

There have been reports of cancer of the gastric remnant occurring in 1.8-5\% of patients who have had surgical treatment for gastric cancer [20, 21]. So the remnant stomach after such treatment is at high risk for the development of metachronous gastric cancer. Several studies show the overall incidence rates of metachronous gastric cancer after endoscopic resection range from 7.9 to $14 \%$ [11, 14-17], and the residual gastric mucosa after such 
Table 3 Clinical characteristics of cases with complications following simultaneous ESD

\begin{tabular}{|c|c|c|c|}
\hline & $\begin{array}{l}\text { With complications, } \\
14 \text { lesions from } \\
7 \text { patients }\end{array}$ & $\begin{array}{l}\text { Without complications, } \\
110 \text { lesions from } \\
55 \text { patients }\end{array}$ & $P$ value \\
\hline Age (years) & $68.0 \pm 10.4$ & $70.9 \pm 9.1$ & 0.434 \\
\hline \multicolumn{4}{|l|}{ Procedure time $(\min )$} \\
\hline Mean $\pm \mathrm{SD}$ & $179.0 \pm 119.0$ & $124.9 \pm 55.5$ & 0.042 \\
\hline$>150$ & $71.4 \%(5 / 7)$ & $29.1 \%(16 / 55)$ & 0.039 \\
\hline \multicolumn{4}{|l|}{ Tumor size (mm) } \\
\hline Mean \pm SD & $12.4 \pm 6.5$ & $13.8 \pm 8.3$ & 0.549 \\
\hline \multicolumn{4}{|l|}{ Tumor size of the larger lesion (mm) } \\
\hline Mean $\pm \mathrm{SD}$ & $14.9 \pm 7.3$ & $18.3 \pm 8.5$ & 0.312 \\
\hline Location & & & 0.714 \\
\hline Upper & $3(21.4 \%)$ & $16(14.5 \%)$ & \\
\hline Middle & $5(35.7 \%)$ & $50(45.5 \%)$ & \\
\hline Lower & $6(42.9 \%)$ & $44(40.0 \%)$ & \\
\hline Location combination & & & 0.572 \\
\hline Upper and upper & $0(0.0 \%)$ & $0(0.0 \%)$ & \\
\hline Upper and middle & $2(28.6 \%)$ & $10(18.2 \%)$ & \\
\hline Upper and lower & $1(14.3 \%)$ & $6(10.9 \%)$ & \\
\hline Middle and middle & $0(0.0 \%)$ & $13(23.6 \%)$ & \\
\hline Middle and lower & $3(42.9 \%)$ & $14(25.5 \%)$ & \\
\hline Lower and lower & $1(14.3 \%)$ & $12(21.8 \%)$ & \\
\hline $\begin{array}{l}\text { Both of the lesions were located in } \\
\text { the same area }\end{array}$ & $1(14.3 \%)$ & $25(45.5 \%)$ & 0.115 \\
\hline $\begin{array}{l}\text { One of the two lesions was located } \\
\text { in the upper portion }\end{array}$ & $42.9 \%(3 / 7)$ & $29.1 \%(16 / 55)$ & 0.457 \\
\hline Guideline criteria & & & 0.480 \\
\hline Standard guideline criteria & $8(57.1 \%)$ & $80(72.7 \%)$ & \\
\hline Expanded indication criteria & $5(35.7 \%)$ & $22(20.0 \%)$ & \\
\hline Non-indication criteria & $1(7.1 \%)$ & $8(7.3 \%)$ & \\
\hline $\begin{array}{l}\text { None of the two lesions were in } \\
\text { the standard guideline criteria }\end{array}$ & $28.6 \%(2 / 7)$ & $9.1(5 / 55)$ & 0.125 \\
\hline
\end{tabular}

Table 4 Clinical characteristics of cases with long procedure times following simultaneous ESD

\begin{tabular}{|c|c|c|c|}
\hline & $\begin{array}{l}\text { Procedure time }>150 \text { min, } \\
42 \text { lesions from } 21 \text { patients }\end{array}$ & $\begin{array}{l}\text { Procedure time } \leq 150 \text { min, } \\
82 \text { lesions from } 41 \text { patients }\end{array}$ & $P$ value \\
\hline Age (years) & $71.0 \pm 10.4$ & $70.4 \pm 8.7$ & 0.830 \\
\hline \multicolumn{4}{|l|}{ Tumor size of the larger lesion $(\mathrm{mm})$} \\
\hline Mean $\pm \mathrm{SD}$ & $22.6 \pm 7.3$ & $15.5 \pm 8.1$ & 0.001 \\
\hline \multicolumn{4}{|l|}{ Location } \\
\hline Upper & $12(28.6 \%)$ & $7(8.5 \%)$ & 0.012 \\
\hline Middle & $17(40.5 \%)$ & $38(46.3 \%)$ & \\
\hline Lower & $13(31.0 \%)$ & $37(45.1 \%)$ & \\
\hline $\begin{array}{l}\text { One of the two lesions were } \\
\text { located in the upper portion }\end{array}$ & $57.1 \%(12 / 21)$ & $17.1 \%(7 / 41)$ & 0.001 \\
\hline \multicolumn{4}{|l|}{ Guideline criteria } \\
\hline Standard guideline criteria & $24(57.1 \%)$ & $64(78.0 \%)$ & 0.048 \\
\hline Expanded indication criteria & $14(33.3 \%)$ & $13(15.9 \%)$ & \\
\hline Non-indication criteria & $4(9.5 \%)$ & $5(6.1 \%)$ & \\
\hline $\begin{array}{l}\text { None of the two lesions were in } \\
\text { the standard guideline criteria }\end{array}$ & $23.8 \%(5 / 21)$ & $4.9(2 / 41)$ & 0.026 \\
\hline
\end{tabular}


treatment is thought to be at a high risk of metachronous gastric cancer. Although the residual gastric mucosa after endoscopic resection is thought to be a high-risk environment, the high risk may only be the result of occult synchronous cancers [17]. Because small lesion size is the major risk factor for endoscopic failure to recognize synchronous additional gastric lesions, the entire stomach should be carefully examined, especially when ESD of gastric cancer is to be performed [10].

In conclusion, simultaneous ESD for synchronous gastric cancer can be a feasible and safe option, and it can reduce hospital stay and overall medical expenses by the resection of two cancers at the same time on the same day. Long operative time is independently associated with complications of simultaneous ESD for synchronous cancer. Size of the larger tumor, upper portion location and tumors not in the standard guideline criteria might be indicators of long procedure time. If a long operative time is predicted, resection on separate days might be a good option to avoid complications.

\section{Conflict of interest None}

\section{References}

1. Gotoda T, Yanagisawa A, Sasako M, Ono H, Nakanishi Y, Shimoda $\mathrm{T}$, et al. Incidence of lymph node metastasis from early gastric cancer: estimation with a large number of cases at two large centers. Gastric Cancer. 2000;3:219-25.

2. Ono H, Kondo H, Gotoda T, Shirao K, Yamaguchi H, Saito D, et al. Endoscopic mucosal resection for treatment of early gastric cancer. Gut. 2001;48:225-9.

3. Neuhaus H, Costamagna G, Deviere J, Fockens P, Ponchon T, Rosch T. Endoscopic submucosal dissection (ESD) of early neoplastic gastric lesions using a new double-channel endoscope (the "R-scope"). Endoscopy. 2006;38:1016-23.

4. Moertel CG, Bargen JA, Soule EH. Multiple gastric cancers; review of the literature and study of 42 cases. Gastroenterology. 1957;32:1095-103.

5. Kosaka T, Miwa K, Yonemura Y, Urade M, Ishida T, Takegawa $\mathrm{S}$, et al. A clinicopathologic study on multiple gastric cancers with special reference to distal gastrectomy. Cancer. 1990;65:2602-5.

6. Esaki Y, Hirokawa K, Yamashiro M. Multiple gastric cancers in the aged with special reference to intramucosal cancers. Cancer. 1987;59:560-5.
7. Kodera Y, Yamamura Y, Torii A, Uesaka K, Hirai T, Yasui K, et al. Incidence, diagnosis and significance of multiple gastric cancer. Br J Surg. 1995;82:1540-3.

8. Honmyo U, Misumi A, Murakami A, Haga Y, Akagi M. Clinicopathological analysis of synchronous multiple gastric carcinoma. Eur J Surg Oncol. 1989;15:316-21.

9. Mitsudomi T, Watanabe A, Matsusaka T, Fujinaga Y, Fuchigami T, Iwashita A. A clinicopathological study of synchronous multiple gastric cancer. Br J Surg. 1989;76:237-40.

10. Lee HL, Eun CS, Lee OY, Han DS, Yoon BC, Choi HS, et al. When do we miss synchronous gastric neoplasms with endoscopy? Gastrointest Endosc. 71:1159-65.

11. Nakajima T, Oda I, Gotoda T, Hamanaka H, Eguchi T, Yokoi C, et al. Metachronous gastric cancers after endoscopic resection: how effective is annual endoscopic surveillance? Gastric Cancer. 2006;9:93-8.

12. Soetikno R, Kaltenbach T, Yeh R, Gotoda T. Endoscopic mucosal resection for early cancers of the upper gastrointestinal tract. J Clin Oncol. 2005;23:4490-8.

13. Japanese Gastric Cancer A. Japanese classification of gastric carcinoma-2nd english edition. Gastric Cancer. 1998;1:10-24.

14. Uemura N, Mukai T, Okamoto S, Yamaguchi S, Mashiba H, Taniyama K, et al. Effect of Helicobacter pylori eradication on subsequent development of cancer after endoscopic resection of early gastric cancer. Cancer Epidemiol Biomark Prev. 1997;6:639-42.

15. Arima N, Adachi K, Katsube T, Amano K, Ishihara S, Watanabe $\mathrm{M}$, et al. Predictive factors for metachronous recurrence of early gastric cancer after endoscopic treatment. J Clin Gastroenterol. 1999;29:44-7.

16. Nasu J, Doi T, Endo H, Nishina T, Hirasaki S, Hyodo I. Characteristics of metachronous multiple early gastric cancers after endoscopic mucosal resection. Endoscopy. 2005;37:990-3.

17. Kobayashi M, Narisawa R, Sato Y, Takeuchi M, Aoyagi Y. Selflimiting risk of metachronous gastric cancers after endoscopic resection. Dig Endosc. 2010;22:169-173.

18. Ohta T, Ishihara R, Uedo N, Takeuchi Y, Nagai K, Matsui F, et al. Factors predicting perforation during endoscopic submucosal dissection for gastric cancer. Gastrointest Endosc. 2012;75:1159-65.

19. Toyokawa T, Inaba T, Omote S, Okamoto A, Miyasaka R, Watanabe $\mathrm{K}$, et al. Risk factors for perforation and delayed bleeding associated with endoscopic submucosal dissection for early gastric neoplasms: analysis of 1123 lesions. J Gastroenterol Hepatol. 2012;27:907-12.

20. Takeda J, Toyonaga A, Koufuji K, Kodama I, Aoyagi K, Yano S, Ohta J, Shirozu K. Early gastric cancer in the remnant stomach. Hepatogastroenterology. 1998;45:1907-11.

21. Hosokawa O, Kaizaki Y, Watanabe K, Hattori M, Douden K, Hayashi H, Maeda S. Endoscopic surveillance for gastric remnant cancer after early cancer surgery. Endoscopy. 2002;34:469-73. 